\title{
THE EFFECTIVENESS OF “CALMING BABY TIPS" IN OVERCOMING CRYING BABIES
}

\author{
${ }^{1}$ Regina VT Novita, ${ }^{2}$ Nunik Yuli Astuti, ${ }^{3}$ Wilhelma Susilo \\ ${ }^{1,2,3}$ Sint Carolus School Health of Sciences, Jakarta, Indonesia \\ Correspondence: regina_vita@yahoo.com
}

\begin{abstract}
Calming baby or 5S's tips can be done using steps such as swaddling, tilting baby (Side or stomach position), shshshs (shushing), swinging and sucking. These interventions support the success of breastfeeding and reduce women's stress and depression during the puerperium. This method is also intended to make the child's growth grow optimally because of the child's energy is fulfilled in the growth period. The purpose of this study was to find out 5S's effectiveness to calm babies when babies cry. The study was conducted in March-August 2016, with a sample of 250 post-partum women in the intervention group and 85 in the control group. This study used quantitative methods with quasi-experimental design and Binary Logistic Regression approach. The results showed that maternal characteristics were not significant (pvalue> 0.05) with the incidence of babies stopping crying. Nagelkerke R square values showed variables such as maternal age, parity, type of labor, education, and work affecting 15.9 times in the calming baby intervention tips so the baby stopped crying. Type of labor was significant to the incidence of babies stopping crying using calming baby tips with a p-value of 0.000 . The results of the interval estimation (95\%) concluded that the calming baby tips after the intervention was 0.194 to 0.62 . This intervention in calming baby tips was effective in stopping crying babies (P Value 0.021). The calming baby tips can be used as educational material for postpartum women.
\end{abstract}

Keywords: 5S's, shushing, sucking, swaddling, swinging.

\section{INTRODUCTION}

One of the goals of the Sustainable Development Goals (SDGs) is to reduce infant mortality. Infant and child mortality rates reflect the level of a country's health and the quality of the citizen. This indicator is also used to monitor and evaluate population and health programs and policies (IDHS, 2012). In Indonesia, the main diseases that cause infant mortality, especially in

Java and Bali, are perinatal disorders, respiratory system diseases, diarrhea, nervous system disorders, other infections and parasites, and tetanus neonatorum. Babies who cry continuously cause their energy to be wasted, this causes weight loss and if it occurs permanently, it will cause babies to be easily exposed to various types of infectious diseases that cause death (Jenskins et al, 2014). Child health expert, Penelope Leach argued that crying for long periods of time causes babies in the risk of developing body damage and reducing their capacity to learn. Babies also 
Regina VT Novita: The Effectiveness Of “Calming Baby Tips” In Overcoming Crying Babies

experience emotional developmental disorders, and if parents do not try to calm their babies who cry continuously, the baby will lose a lot of energy that is actually needed for their growth and development (UNICEF, 2011)

Crying is a way of newborns to communicate with others especially parents. Crying babies are a natural thing, but if it too long it can be a sign of health problems. According to Jufrrie, if a baby cried more than three hours, maybe he/she has the abdominal colic (Tempo, 2014). Baby crying shows their different needs, such as signs of discomfort, asking for help, hunger, thirst, pain, general discomfort (wanting to change position, cold, or heat), boredom, loneliness, or a desire for physical and social contact (Diane, 2008). Touch or voice would provide comfort for the baby. Naturally, a mother would carry, swing, and breastfeed when the baby cries until the baby is calm (Dubinsky, 2012). Babies become calm down when mothers do body movements that are usually done to calm them down like touch because babies feel protected by their parents

In The Happiest Baby on The Block book, Harvey Karp said the best way to calm babies is to recreate sounds, movements and a comfortable environment like in the womb. Calming baby or steps to calm the baby is done by swaddling, giving a side position (stomach/position), constant sound (Shushing), and swinging (sucking) (Karp, 2008). Swaddling with blankets increase the duration of babies' sleep time for half to one hour at night, significantly $(\mathrm{p}<0.05)$ (McRurry \& Zolotor, 2010) and surveys at the University of Arizona found the THB (The Happiest Baby on the Block) in parents including tips for calming babies, significantly increasing parents' confidence in calming their babies when crying showing ( $\mathrm{p}<0.01)$ (UA, 2010). 
Babies who routinely received calming baby tips had better in storing energy, which reduced because of crying babies. Research conducted by John, et al (2012), swaddling, sideways position, constant sound, swinging and sucking, reduced pain and the intensity of crying babies after vaccination. Research by Harrington et al. (2012) showed 5S's technique independently can reduce post vaccination pain without sucrose administration. The method of calming the baby aimed to make the child's growth and development more optimal because of sufficient energy during the growth period. According to Manaseki-Holland et al. (2010), on a large scale, there was no significant impact of swaddling on the psychomotor or mental development of children, it was based on findings in many developing countries that millions of babies were swaddling every year. In Nicholas Clarke (Maloy, 2013) said tight swaddling basically limits the movement of the baby and it can endanger the development of the baby's hip joint. This is supported by Aryadi Kurniawan, a pediatric orthopedic expert that tightly swaddling has the potential to development of Hip Dysplasia (DDH) (Tempo, 2014).

Finding an effective strategy or method for reducing baby crying is not easy. Unstable baby's behavior, such as continuous crying, results in parents' tiredness. Inappropriate handling of babies by parents when crying would be caused various problems such as babies experiencing stomach colic followed by reflux, maternal-infant bonding disorders, and the possibility of sudden infant death syndrome (Karp, 2008). Professional health workers are needed to overcome the problems faced by parents in caring for their babies. Nursing practice has an important role in the baby's health. The right treatment strategy would reduce the frequency of crying and maternal fatigue when caring for the baby so that it has the potential to strengthen family health from the initial stage. (Kurth et al, 2009). 
Regina VT Novita: The Effectiveness Of “Calming Baby Tips” In Overcoming Crying Babies

A Tangerang and S Jakarta Hospital concern in improving the quality of services in all fields including applying the rooming-in method for all types of deliveries with the criteria of healthy babies. In RS A in 3 months there were 152 deliveries with cesarean surgery and 142 normal deliveries, while S Hospital had 84 deliveries with cesarean section and 175 normal deliveries. Services in both hospitals support 10 LMKM programs (Steps to Success in Breastfeeding) including counseling about breastfeeding, a problem often encountered is that mothers are unable to breastfeed because the mother is unable to calm her baby when crying and fussing. The results of unstructured interviews at Jakarta C Hospital and Hospital A, mothers said they did not know how to calm their babies. They knew one or two ways, namely holding while shaking, but it is not effective to calm the baby. Based on the description, researchers are interested in examining the effectiveness of calming baby tips, to deal with crying babies. This research is expected to contribute to improving nurses' intervention skills and increasing mothers' knowledge to calm their babies.

\section{METHODS}

This study used quantitative methods with quasi-experimental design and binary logistic regression approach. This study examined the effectiveness of the variable calming baby tips (swapping, shushing, side position, swinging), infant weight, maternal age and parity with the dependent variable the level of the Baby Stop Crying. The population of this study was mothers who have babies aged 0 - 3 days. The sampling technique used total sampling. 250 postpartum mothers for the intervention group and the control group 85 postpartum mothers. Data were collected using the observation sheet, the data collection process in the control group was an observation when the baby cried, and what techniques the mother did to calm the baby. The 
intervention group provides a counseling technique to calm the baby. The exclusion criteria in this study were mothers experiencing postpartum depression, mothers were unwilling to become respondents. This was in accordance with the Thabane formula where the intervention group $75 \%$ and control $25 \%$. Univariate analysis is presented in the form of frequency distribution, spread size, an average value.

\section{RESULT}

\section{Univariate Analysis}

Table 1 Characteristics of Respondents

\begin{tabular}{lcccc}
\hline \multirow{1}{*}{ Characteristics } & \multicolumn{2}{c}{ Intervention } & \multicolumn{2}{c}{ Control } \\
\cline { 2 - 5 } Arequency & Percent & Frequency & Percent \\
\hline $0-30$ & 150 & 60.00 & 51 & 60,0 \\
$31-42$ & 100 & 40.00 & 34 & 40,0 \\
\hline Parity & & & & \\
Prim parous & 75 & 30.00 & 19 & 22.40 \\
Multi parous & 175 & 70.00 & 66 & 77.60 \\
\hline Type of deliveries & & & & \\
Normal & 98 & 39.20 & 39 & 45.90 \\
Caeseran delivery & 152 & 60.80 & 46 & 54.10 \\
\hline Job & & & & \\
Working & 158 & 63.20 & 45 & 52.90 \\
Jobless & 92 & 36.80 & 40 & 47.10 \\
\hline Education & & & & \\
Elementary & 2 & 0.80 & - & - \\
Junior High School & 18 & 7.20 & 9 & 10.60 \\
Senior High School & 107 & 42.80 & 35 & 41.20 \\
Diploma & 48 & 19.20 & 14 & 16.50 \\
University & 75 & 30.00 & 27 & 31.80 \\
\hline Baby weight & & & & \\
2500-3500 gram & 124 & 49.60 & 78 & 91.00 \\
$>$ 3500 gram & 126 & 50.40 & 7 & 9.00 \\
\hline Baby crying & & & & \\
Crying & 115 & 46.00 & 37 & 43.50 \\
Stop Crying & 135 & 54.00 & 48 & 56.50 \\
\hline Baby stop crying & 19 & 7.60 & 20 & 23.50 \\
Swaddling & 60 & 10.40 & 18 & 21.20 \\
Positioning & 24.00 & 26 & 30.60 \\
Shushing & & & & \\
\hline
\end{tabular}

JMCRH: Vol. 1 Issue 2 
Regina VT Novita: The Effectiveness Of “Calming Baby Tips” In Overcoming Crying Babies

\begin{tabular}{lllll}
\hline Swinging & 49 & 19.60 & 11 & 12.90 \\
Sucking & 96 & 38.40 & 10 & 11.90 \\
\hline
\end{tabular}

Table 1 shows the frequency distribution of respondent characteristics based on age, parity, type of delivery, occupation and infant weight in the intervention and control groups. The majority of respondents were 20-30 years old both in the intervention and control groups. Based on parity, most of the respondents were multiparous, with the type delivery was cesarean surgery. High school education and work status were dominant in the intervention and control groups. The intervention group gave birth to a baby with a birth weight more than 3500 grams $(50.40 \%)$, while in the control group the baby weight was $2500-3500$ grams, $91 \%$ breastfeed their baby, and $30.60 \%$ did shushing.

\section{Bivariate analysis}

Table 2 The Relationship among Characteristics of Respondents and Calming Baby Tips

\begin{tabular}{|c|c|c|c|c|c|c|c|}
\hline \multirow[t]{2}{*}{ Characteristic } & \multicolumn{5}{|c|}{ Calming Baby Tips } & \multirow{2}{*}{$\%$} & \multirow{2}{*}{$\begin{array}{c}\mathbf{P} \\
\text { value }\end{array}$} \\
\hline & Swaddling & Position & Shushing & Swinging & Breastfeed & & \\
\hline \multicolumn{8}{|l|}{ Age } \\
\hline $20-30$ & $19,3 \%$ & $21,3 \%$ & $18,0 \%$ & $19,3 \%$ & $22,0 \%$ & \multirow{3}{*}{$\begin{array}{l}100 \\
100\end{array}$} & \multirow[t]{2}{*}{.736} \\
\hline $31-42$ & $21,0 \%$ & $18,0 \%$ & $23,0 \%$ & $21,0 \%$ & $17,6 \%$ & & \\
\hline Baby's weight & & & & & & & .797 \\
\hline $2500-3500 \mathrm{gr}$ & $17,7 \%$ & $21,0 \%$ & $22,6 \%$ & $19,4 \%$ & $19,4 \%$ & 100 & \\
\hline$>\quad 3500 \mathrm{gr}$ & $22.2 \%$ & $19,0 \%$ & $17,5 \%$ & $20,6 \%$ & $20,6 \%$ & & \\
\hline \multicolumn{8}{|l|}{ Parity } \\
\hline Multiparous & $19,4 \%$ & $21,1 \%$ & $21,1 \%$ & $18,9 \%$ & $19,4 \%$ & 100 & \multirow[b]{2}{*}{.856} \\
\hline Primparous & $21,3 \%$ & $17,3 \%$ & $17,3 \%$ & $22,7 \%$ & $21,3 \%$ & 100 & \\
\hline \multicolumn{8}{|l|}{ Type deliveries } \\
\hline Spontan & $19,4 \%$ & $17,3 \%$ & $19,4 \%$ & $21,4 \%$ & $22,4 \%$ & 100 & \multirow[t]{2}{*}{.866} \\
\hline $\mathrm{SC}$ & $20,4 \%$ & $21,7 \%$ & $20,4 \%$ & $19,1 \%$ & $18,4 \%$ & 100 & \\
\hline \multicolumn{8}{|l|}{ Working } \\
\hline Unemployment & $22,8 \%$ & $14,1 \%$ & $20,7 \%$ & $18,5 \%$ & $23,9 \%$ & 100 & \multirow[t]{2}{*}{.354} \\
\hline Employment & $18,4 \%$ & $23,4 \%$ & $19,6 \%$ & $20,9 \%$ & $17,7 \%$ & 100 & \\
\hline \multicolumn{8}{|l|}{ Education } \\
\hline SD & $0,0 \%$ & $50,0 \%$ & $50,0 \%$ & $0,0 \%$ & $0,0 \%$ & 100 & \multirow[t]{3}{*}{.713} \\
\hline SMP & $27,8 \%$ & $5,6 \%$ & $27,8 \%$ & $22,2 \%$ & $16,7 \%$ & 100 & \\
\hline SMA & $17,8 \%$ & $17,8 \%$ & $18,7 \%$ & $23,4 \%$ & $22,4 \%$ & 100 & \\
\hline
\end{tabular}


Regina VT Novita: The Effectiveness Of “Calming Baby Tips” In Overcoming Crying Babies

\begin{tabular}{lllllll} 
Diploma & $16,7 \%$ & $29,2 \%$ & $14,6 \%$ & $18,8 \%$ & $20,8 \%$ & 100 \\
PT & $24,0 \%$ & $20,0 \%$ & $22,7 \%$ & $16,0 \%$ & $17,3 \%$ & 100 \\
\hline
\end{tabular}

Table 2 shows that mothers aged 31-42 years were able to calm crying babies using calming baby tips especially with shushing actions (23\%). The results of the analysis used that Chi-square test obtained by pValue 0.736 at alpha 0.05 means that there is no relationship between maternal age and the incidence of babies stopping crying using calming baby tips. The results of this study were in opposite with Morris's (2013) study found that in the 2008 era many primiparous women at the age of 40 years had complications during pregnancy and childbirth, and had difficulty calming babies, especially when fussy or crying because they were experiencing anxiety. Researchers' perceived that increasing maternal age would increase stress levels in the period of pregnancy, labor and postpartum. Self-anxiety would have a negative impact on the baby, so the baby cries without being stopped.

The results showed that the use of calming baby tips with shushing actions in babies weighing 2500-3000 grams was able to stop the baby crying of $22.6 \%$. The results of the analysis using the Chi-square test results obtained P Value 0.797 at alpha 0.05 , which means that there is no relationship between infant weight and the incidence of babies stopping crying using calming baby tips. The assumption of researchers was the body weight more than 2500 grams can be said to be healthy so that it can receive immunization. In the McRury (2011) study, the Calming baby Tips action, 5S's was able to reduce pain after immunization, marked by the cessation of babies crying.

This study found that the use of calming baby tips by swinging on primiparous mothers was able to stop crying by $22.7 \%$. The results of the analysis using the Chi-square test results obtained P Value 0.856 at alpha 0.05 , which means there is no relationship between parity with 
the incidence of babies stopping crying using calming baby tips. The results of this study are in accordance with the study of Schytt (2005) and Dewar (2009) found prim parous women 46-87\% complained of being tired of taking care of their babies, especially when fussy and crying. Mothers who are depressed or anxious will find it difficult to calm their crying babies and that babies cry because of negative emotions from their mothers and directly affect their babies. Researchers' assumed that mothers who have just given birth first need time to balance the ability to care for the baby and himself. This inability may be because mothers need to adapt to their baby's habits, and still lack the confidence of the mother in caring for her baby.

The analysis showed the use of calming baby tips with breastfeeding in mothers with vaginal delivery, babies were able to stop crying by $22.4 \%$. The results of the analysis using the Chi-square test results obtained $\mathrm{P}$ Value 0.866 at alpha 0.05 , which means there is no relationship between the type of labor with the incidence of babies stopping crying using calming baby tips. The results of this study are not in accordance with the study of Kurth (2010), where the inability of mothers to calm their crying babies is a complaint that is often expressed in postpartum mothers with a cesarean section to health workers. Mothers who experience cesarean section will find it difficult to contact the baby, this affects the crying baby (Dalbye, 2011). Researchers' perception, mothers who have just given birth first give high energy so that they are tired or tired after giving birth. Babies need adaptation between intra and extrauterine. Prolonged labor and pain due to cesarean section greatly influence the mother's ability to calm her newborn baby.

Table 2 shows the use of calming baby tips with breastfeeding for mothers who unemployment, babies can stop crying by $23.9 \%$. The results of the analysis using the Chi-square test results obtained P Value 0.354 at alpha 0.05 , which means there is no relationship between 
types of work with the incidence of babies stopping crying using calming baby tips. The results of this study are incompatible with Lan's (2011) study, saying working mothers are a major factor in the failure of exclusive breastfeeding so working mothers who fail exclusive breastfeeding and find it difficult to calm their crying or fussy babies. The researcher perceived that a mother who experiences cesarean section will experience difficulties in initiating early breastfeeding, and is one factor in the failure of breastfeeding, this will have an impact on the mother's inability to calm her baby.

The results of this study also showed that the relationship of using calming baby tips and swaddling and shushing actions for mothers with junior high school education where babies are able to stop crying by $27.8 \%$. The results of the analysis using the Chi-square test results obtained P Value 0.713 at alpha 0.05 , which means there is no relationship between education and the incidence of babies stopping crying using calming baby tips. The results of this study are consistent with the research of McRury et al. (2010) which states that the behavior of mothers when caring for babies is not effective in reducing infant crying even though mothers have been given knowledge or education through videotapes about how to calm newborns. Assuming researchers, highly educated mothers do not necessarily have high health knowledge. Therefore knowledge in the form of information about calming baby tips is very important given to the prenatal class so that the mother and family have the ability to calm their babies in the early period after birth.

\section{Analysis Multivariate The Application of The Regression Logistic Binary}

Table 3 Model Regresi Appropriateness

\begin{tabular}{cccc}
\hline Step & Chi-square & Df & Sig. \\
\hline 1 & 42,952 & 7 &, 000 \\
\hline
\end{tabular}


Regina VT Novita: The Effectiveness Of “Calming Baby Tips” In Overcoming Crying Babies

\begin{tabular}{llll}
\hline 2 & 50,049 & 7 &, 000 \\
3 & 43,584 & 8 &, 000 \\
4 & 16,536 & 7 &, $\mathbf{0 2 1}$ \\
\hline
\end{tabular}

The feasibility of the regression model with Hosmer and Lemshow's Goodness of Fit Test predicts the observation value so that the model is known to be acceptable or not (according to or not by observation). All models fit where significance values> 0.05. The table above explains that the intervention tips for calming baby effect on infants stopped responding with the significance value was 0.021 .

Table 4 Uji Regresi Logistik Binary

\begin{tabular}{|c|c|c|c|c|c|}
\hline \multirow[t]{2}{*}{ Characteristic } & \multirow[t]{2}{*}{ Df } & \multirow[t]{2}{*}{ Sig. } & \multirow[t]{2}{*}{$\operatorname{Exp}(B)$} & \multicolumn{2}{|c|}{$\begin{array}{c}\text { 95\% C.I.for } \\
\text { EXP(B) }\end{array}$} \\
\hline & & & & Lower & Upper \\
\hline Age & 1 &, 730 & 1,109 & ,616 & 1,998 \\
\hline weight & 1 & ,383 & 1,275 &, 738 & 2,204 \\
\hline Parity & 1 & 047 &, 521 & 273 & ,992 \\
\hline Delivery type & 1 &, 000 & ,347 & 194 & 620 \\
\hline Employment & 1 &, 748 & 901 & 476 & 1,705 \\
\hline Education & 1 &, 025 & 1,450 & 1,048 & 2,005 \\
\hline
\end{tabular}

The results in table 9 show that the type of labor was significant to the incidence of babies stopping crying using calming baby tips with a p-value of 0.000 , The results of the interval estimation (95\%) that calming baby tips after intervention 0.194 to 0.620 . The results of this study are in accordance with Kurth (2010) and Dalbye (2011), who said that fatigue and pain factors were the main factors in postpartum mothers with cesarean section. Delay in early breastfeeding is closely related to depression experienced by the mother which would affect the incidence of spontaneous colic (Sung, 2014). The inability of the mother to calm her crying baby is a complaint that is often expressed in postpartum mothers with cesarean section. Mothers who experience cesarean section would The feasibility of the regression model with Hosmer and Lemshow's Goodness of Fit Test predicts the observation value so that the model is known to be acceptable or not (according to or not by observation). All models fit where significance values> 
0.05. The table above explains that the intervention tips for calming baby affect on infants stopped responding where the significance value was 0.021 . The feasibility of the regression model with Hosmer and Lemshow's Goodness of Fit Test predicts the observation value so that the model is known to be acceptable or not (according to or not by observation). All models fit where significance values $>0.05$. The table above explains that the intervention tips for calming baby affect on infants stopped responding where the significance value was 0.021 . have difficulty in skin contact between mother and baby, this affects the crying baby.

\section{Table 5. Uji Nagelkerke R Square}

\begin{tabular}{cccc}
\hline Step & $\begin{array}{c}\mathbf{- 2} \text { Log } \\
\text { likelihood }\end{array}$ & $\begin{array}{c}\text { Cox \& Snell R } \\
\text { Square }\end{array}$ & $\begin{array}{c}\text { Nagelkerke } \\
\text { R Square }\end{array}$ \\
\hline 1 & $312,311^{\mathrm{a}}$ &, 122 &, 164 \\
& $312,414^{\mathrm{a}}$ &, 122 &, 163 \\
3 & $312,553^{\mathrm{a}}$ &, 122 &, 163 \\
4 & $313,356^{\mathrm{a}}$ &, 119 &, 159 \\
\hline
\end{tabular}

Table 10 shows the Nagelkerke R square value based on the dependent variable (Y) which are the baby stops crying or does not stop crying, it is explained by the variability of independent variables (maternal age, parity, type of labor, education, and employment) with a value of 15.9 times. This means that the independent variable affects 15.9 times in the calming baby intervention tips so the baby stops crying. This is supported by Morris (2013) study, in the era before 2008, primiparous women at the age of 40 years had a greater risk of complications of pregnancy and childbirth, and might have an impact on women experiencing anxiety disorders which resulted in the mother having difficulty calming the baby especially when fussy or crying. In parity and type of labor according to Kurth (2010) a young mother took time to take care of herself, she needed family help to take care her baby especially when her baby is fussy and crying. Cesarean delivery, fatigue, and pain are the main factors of mother's inability to calm her crying baby. Women with cesarean would have difficulties to contact with babies, this has an 
Regina VT Novita: The Effectiveness Of “Calming Baby Tips” In Overcoming Crying Babies

effect on crying babies (Dalbye, 2011). Maternal education given is not necessarily able to change a person's behavior. This is supported by the research of McRury et al. (2010) that the behavior of mothers when caring for babies is not effective in reducing baby cries even though mothers have been given health education via videotapes to calm their babies.

\section{CONCLUSION}

Crying is a significant sign and response of a baby who is experiencing pain. A baby who felt pain and managed effectively by the mother, it means the baby has a healthy newborn period (Yilmaz \& Arikan, 2010). Mothers who are able to breastfeed well will be able to calm crying babies significantly. Maximum breastfeeding activities are supported by early initiation carried out in the first hour. Mothers who had cesarean delivery section would late in early initiation of breastfeeding, and working mothers are another factor in exclusive breastfeeding failure (Lan, 2011). Working mothers who fail exclusive breastfeeding will find difficulty in calming their crying or fussy babies (Schytt, 2005). The results showed that the Calming Baby Tips intervention when it carried out effectively was able to calm the baby, and it depends on the type of labor with a p-value 0.000 . The results of the interval estimation value (95\%) after the intervention of calming baby tips was 0.194 to 0.620 in the intervention group.

\section{REFERENCES}

Diane M. Fraser, M. A. (2008). Survival Guide To Midwifery. Philadelphia.

Dalbye, R. Et al, (August 2011). Mothers' experiences of skin-to-skin care of healthy full-term newborns - A phenomenology study, Sexual \& Reproductive Health Care Journal, vol.

2, Issue 3, P:107-111, diunduh http://www.srhcjournal.org/article. 
Regina VT Novita: The Effectiveness Of “Calming Baby Tips” In Overcoming Crying Babies

Dewar, Gwen (2009). Excessive infant crying and irritability: Which comes first - the unhappy baby or the unhappy parent?. From http://www.parentingscience.com/infant-crying-andparenting-stress.html.

Dubinsky, D. (2012, September). Harvey Karp's "Happiest Baby" method for baby sleep and soothing. Retrieved Mei 22, 2015, diunduh http://www.babycenter.com/0_harvey-karpshappiest-baby-method-for-baby-sleep-and-soothin_10373838.bc.

Harrington, JW., et al., (May 2012). Effective Analgesia Using Physical Interventions for Infant Immunizations, Pediatrics journal, Vol 129/issue 5. Diunduh http://pediatrics.aappublications.org/content/129/5/815.short .

Harvey Karp, M. (2008). The Happiest Baby on the Block. Random House Publishing Group.

Jenskins, D. S. (2014). Guideline for Family Centred Developmental Care. The Northern Neonatal Network, 17.

John W. Harrington, M., Stacey Logan, M., Courtney Harwell, M., Jessica Gardner, M., Jessica Swingle, B., Erin McGuire, M., \& Rosemarie Santos, M. (2012). Effective Analgesia Using Physical Interventions for Infant Immunizations. the American Academy of Pediatrics. doi:10.1542/peds.2011-1607 .

McRury, M., \& Adam J. Zolotor, M. M. (2010). A Randomized, Controlled Trial of a Behavioral. the American Board Of Family Medicine.

Karp, H. (2008, April 5). Five Simple Steps to Calm Your Baby’s Fussies! Retrieved Mei 26, 2015, from http://www.happiestbaby.com/five-simple-steps-to-calm-your-babys-fussies/ .

Kurth, et. Al, (May, 2010). Crying babies, tired mothers-challenges of the postnatal hospital stay: an interpretive phenomenological study. BMC Pregnancy and Childbirth, 10:20, DOI: 10.1186/1471-2393-10-21, from http://bmcpregnancychildbirth.biomedcentral.com/articles.

Kompas. (2011, Maret 14). Bayi Haus Terus ASI-nya Kurang? Retrieved Juli 10, 2015, from http://health.kompas.com/read/2011/03/14/11420357/Bayi.Haus.

Kurth E, Kennedy H.P., Spichiger, E., Hösli, Stutz, EZ. (2009). Crying babies, tired mothers: What do we know? A systematic review, from http://www.midwiferyjournal.com/article, DOI: http://dx.doi.org/10.1016/j.midw .

Lan, KL., (Feb, 2011). Factors associated with exclusive breastfeeding among infants under six months of age in peninsular malaysia, International Breastfeeding Journal, DOI: 10.1186/1746-4358-6-2. Diunduh 
Regina VT Novita: The Effectiveness Of “Calming Baby Tips” In Overcoming Crying Babies

https://internationalbreastfeedingjournal.biomedcentral.com/articles/10.1186/17464358-6-2.

Maloy, O. (2013). Could Swaddling Damage Your Baby's Hips? Children's \& Teens Health. Retrieved Juni 27, 2015, from http://www.steadyhealth.com/articles .

Manaseki-Holland, S., Spier, E., Bavuusuren, B., Bayandorj, T., \& Marshall, S. S. (2010). Effects of Traditional Swaddling on Development: A Randomized Controlled Trial. the American Academy of Pediatrics. doi:10.1542/peds.2009-1531.

McKinney, S. S. (2010). Foundations of Maternal-Newborn and Women's Health Nursin. Canada: Jeff Patterson.

McRury, JM., Zolotor, JM. (2010), A randomized, controlled trial of a behavioral intervention to reduce crying among infants. Journal of The America Board of Family Medicine, vol. 23/3, page:315-322. doi: 10.3122/jabfm.2010.03.090142. From http://www.jabfm.org/content/23/3/31.

Morris Psychological Group., (June, 2013). Postpartum Depression: Are Older Mothers More at Risk?, from http://www.morrispsych.com/postpartum-depression-are-older-mothersmore-at-risk/.

Rustika, S. dan Sudibyo. (2013). Metodologi Riset Keperawatan. Jakarta : TIM.

Schytt., Lindmark., Waldenstrom., (2005). Physical symptoms after childbirth: prevalence and associations with self-rated health. BJOG. 112 (2): 210-217. 10.1111/j.14710528.2004.00319.x. from http://bmcpregnancychildbirth.biomedcentral.

Sugiyono. (2009). Metode Penelitian Kuantitatif, Kualitatif dan Kombinasi. Jakarta : Alfabeta.

Survei Demografi dan Kesehatan Indonesia (SDKI). 2012. Ini Sebabnya Angka Kematian Pada Bayi Baru Lahir di Indonesia Susah Turun. Retrieved Juli 11 2015, from http://m.detik.com/health/read/2013/02/27/152325/ Ini-sebabnya-angka-kematian-padabayi-baru-lahir-di -indonesia-susah-turun.

Susilo, WH., Aima, HM., \& Suprapti, F. (2014). Biostatistika Lanjut dan Aplikasi Riset. Jakarta: CV. TRANS INFO MEDIA.

Sung, V, et all. (April, 2014). Treating infant colic with the probiotic Lactobacillus reuteri: double blind, placebo controlled randomised trial.

Tempo. (2014, Oktober 24). Bedong Ketat Sebabkan Panggul si Kecil Bergeser? Retrieved Juni 19, 2015, from http://gaya.tempo.co/read/news/2014/10/24/29 . 
UA Evaluation Research and Development Team. (21 July, 2010). SEABHS:Data Summary of Happiest Baby on the Block Retrospective Post-Test Surveys: FY: 2007-2008. Available at http://www.thehappiestbaby.org/thbe-univ-az-study-2008.pdf.

UNICEF, W. \&. (2011). Pelatihan Konseling Menyusui Modul 40 Jam WHO/UNICEF : Panduan Fasilitator.

Yilmaz, F., Arikan, D., (Nov, 2010). The effects of various interventions to newborns on pain and duration of crying, Jounal of Clinical Nursing, DOI: 10.1111/j.13652702.2010.03356.x, Vol 20, Issue 7-8. Available http://onlinelibrary.wiley.com/doi/10.1111/j.1365-2702.2010.03356.x/full 